\title{
Treatment options in extra-articular distal radius fractures: a systematic review and meta-analysis
}

\author{
Guido W. Van Oijen ${ }^{1}$ - Esther M. M. Van Lieshout ${ }^{1}$ (1) $\cdot$ Maarten R. L. Reijnders $^{1} \cdot$ Anand Appalsamy $^{1}$. \\ Tjebbe Hagenaars $^{1} \cdot$ Michael H. J. Verhofstad ${ }^{1}$
}

Received: 17 January 2021 / Accepted: 19 April 2021 / Published online: 19 May 2021

(c) The Author(s) 2021

\begin{abstract}
Purpose This systematic literature review aimed to make a detailed overview on the clinical and functional outcomes and to get insight into the possible superiority of a treatment method for extra-articular distal radius fractures.

Methods Embase, Medline, Cochrane Library, Web of Science, and Google Scholar were searched for studies describing treatment results. Five treatment modalities were compared: plaster cast immobilization, K-wire fixation, volar plating, external fixation, and intramedullary fixation.

Results Out of 7,054 screened studies, 109 were included in the analysis. Overall complication rate ranged from $9 \%$ after plaster cast treatment to $18.5 \%$ after K-wire fixation. For radiographic outcomes, only volar tilt in the plaster cast group was lower than in the other groups. Apart from better grip strength after volar plating, no clear functional differences were found across treatment groups.

Conclusion Current literature does not provide uniform evidence to prove superiority of a particular treatment method when looking at complications, re-interventions, and long-term functional outcomes.
\end{abstract}

Keywords Review $\cdot$ Distal radius fractures $\cdot$ Extra-articular $\cdot$ Treatment $\cdot$ Non-operative $\cdot$ Operative

\section{Introduction}

A large variety exists in distal radius fractures; from highenergy, comminuted, intra-articular fractures, to low-energy, simple extra-articular fractures. Because of the difference in bone quality, fracture characteristics, associated soft tissue injury, and patient's needs between these groups, a different treatment approach might be necessary [1-3].

Fractures of the distal radius can be treated operatively or non-operatively. Closed reduction and plaster cast immobilization was traditionally preferred for both intra- and extraarticular fractures. Devices for operative treatment, such as Kirschner wires, plates, external fixators, and intramedullary implants, have been introduced over the last decades and their appropriate use yields good functional results [4-6]. Especially the introduction of volar locking plates has led

Esther M. M. Van Lieshout

e.vanlieshout@erasmusmc.nl

1 Trauma Research Unit, Department of Surgery, Erasmus MC, University Medical Center Rotterdam, P.O. Box 2040, 3000 CA Rotterdam, The Netherlands to a significant increase in operative treatment rates, also for extra-articular fractures, because of the improvement in stability and therefore the possibility for early mobilization [7]. On the other hand, complaints and complications from tendon irritation are assumed more common and the extensive dissection of soft tissue might cause fracture and wound healing problems [7]. Other operative treatments also provide better stability than plaster casting, but have their own cons [8-10].

Current guidelines suggest closed reduction and plaster cast immobilization as the primary treatment for extraarticular distal radius fractures because the treatment is non-invasive and cheap $[11,12]$. However, it is unclear if a non-invasive method also means fewer complications and an acceptable loss of function. There is still no consensus regarding the superiority of one of these methods for treating extra-articular distal radius fractures.

The aim of this systematic literature review and metaanalysis was to make a detailed overview on the clinical and functional outcomes and to get insight into the possible superiority of a treatment method in adult patients with an extra-articular distal radius fracture. 


\section{Materials and methods}

\section{Search strategy}

A literature search was conducted June 19, 2018. Embase, Medline, The Cochrane Library, Web of Science, and Google Scholar were searched to identify relevant clinical studies that report on the outcomes of extra-articular distal radius fractures. De-duplication of studies was performed as described before [13]. The exact search strategy for the different databases is shown in Online Appendix 1. No language limits were used and any potentially eligible non-English language manuscripts were translated if possible by native speaking colleagues or using Google translate, if no native speaker was available.

\section{Selection criteria}

The studies were eligible for inclusion if they met the following criteria: (1) Patients who suffered and were treated for an extra-articular distal radius fracture; (2) age 18 years or older; (3) patients were either treated using a plaster cast, K-wire(s), plate fixation, external fixator, or an intramedullary device; (4) primary data for at least one outcome parameter had to be available.

Studies without a clear description of fracture type or intervention, or studies that lacked sufficient data for analysis were excluded. In addition, studies with incomplete registration of complications were excluded. Studies describing a not-commonly used device or technique for extra-articular fractures were excluded (i.e. dorsal plates, Epibloc system, cannulated screw, above elbow cast, etc.). If a study consisted of one eligible and one non-eligible cohort, this study was included in our study, but only if data for the eligible group was provided.

Two authors (GWVO and AA) independently screened the search results for potentially eligible studies by checking the title and abstract in phase one. Any disagreement has been resolved by consensus or consultation of a third author (TH). After the exclusion of all irrelevant studies, the full text of the remaining studies was obtained, and the eligibility was evaluated to complete selection in phase two. This again was done independently by two authors (GWVO and MRLR). Any disagreement was resolved as described above. If the full-text study was not available, the corresponding author was contacted and asked.

The study protocol has not been registered or published before.

\section{Data extraction}

In phase three, the same two authors independently extracted the following data from the included studies: author, year of publication, study design, type of treatment, number of patients, mean age of patients, number of female patients, duration of follow-up, and type of fracture classification. The outcome data that were retrieved, consisted of; complications and re-interventions, radiographic outcomes (i.e. consolidation rate, volar/dorsal tilt, radial inclination, radial height, and ulnar variance), range of motion, grip strength, and functional outcome scores (i.e. Disabilities of the Arm, Shoulder, and Hand (DASH) score, Quick-DASH score, Patient Rated Wrist Evaluation (PRWE-)score, Visual Analog Scale (VAS) for pain, Gartland and Werley score, and the Mayo Wrist Score). All outcome data were pooled for four different follow-up periods: 0-3 months, $>3-6$ months, > 6-12 months, and 12 months or longer (long term).

\section{Quality assessment}

Risk of bias and methodological quality of the included studies were assessed using the Newcastle-Ottawa Quality Assessment Scale. This scale results in a score ranging from 0 to 9 . Scores of 8 and 9 were defined as high-quality studies, scores of 5-7 were defined as medium quality, and scores of 1-4 were defined as low quality [14].

\section{Data analysis}

Meta-analysis for binary data was performed using MedCalc for Windows. Heterogeneity testing was performed using Cochran's $\mathrm{Q}$ and the $\mathrm{I}^{2}$ statistic. $\mathrm{Q}$ is distributed as a chisquare statistic with $\mathrm{k}$ (number of studies) minus 1 degrees of freedom. Q has low power as a comprehensive test of heterogeneity [15]. The $\mathrm{I}^{2}$ statistic describes the percentage of variation across studies that is due to heterogeneity rather than chance $[16,17]$. A random-effects model was used if the $\mathrm{I}^{2}$ value was larger than $40 \%$. When the $\mathrm{I}^{2}$ was lower than $40 \%$ a fixed-effects model was used. Pooled estimates (i.e., proportion) are reported with their $95 \%$ confidence intervals (CI). When there was no overlap in the $95 \%$ confidence intervals, the difference was considered statistically significant. For the continuous data a pooled estimate (i.e., mean) was calculated in Microsoft Excel, using sample size as a weighting factor. Since most studies only provided the mean values but no standard deviation, $95 \%$ confidence interval, or standard error, a formal meta-analysis was not feasible for the continuous data.

\section{Results}

The primary search resulted in 14,398 hits and after deduplication 7054 studies remained. After screening these studies by title and abstract 1137 remained for full-text evaluation. A total of 109 studies, with 136 different cohorts 
were marked eligible for the analysis (Fig. 1 and Supplementary Table S1). These 136 cohorts consisted of a total of 6707 patients divided over the five different treatment modalities. The pooled average age and gender of patients for each treatment method are outlined in Table 1.

Among the 109 studies were 21 randomized controlled trials, 37 prospective studies, and 51 retrospective studies (Supplementary Table S1). Among the 136 cohorts, 31 reported on outcomes after plaster cast immobilization [18-48], 37 on K-wire fixation [5, 18, 21, 41, 42, 45, $47,49-76], 41$ on volar plate fixation $[4-6,54-56,60,61$, $72,74,77-107], 16$ on external fixation $[6,30,34,36,53$,
108-118], and 11 on intramedullary fixation [4, 6, 43, 81, 92, 96, 119-123]. Most of the included studies were of low or medium quality, $40 \%(N=44)$ and $50 \%(N=55)$, respectively. Ten of the included studies were of high quality, as outlined in Supplementary Table 2.

\section{Complications}

The pooled overall complication rate ranged from $9 \%$ after plaster cast treatment to $19 \%$ after K-wire fixation (Table 2). Superficial infections were most prominent and higher in the K-wire (4.7\% [95\% CI 2.5-7.6\%]) and ExFix

\section{PFISMA PRISMA 2009 Flow Diagram}
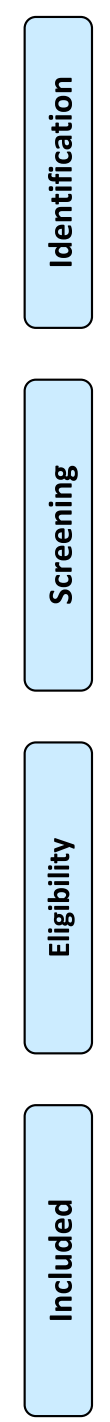

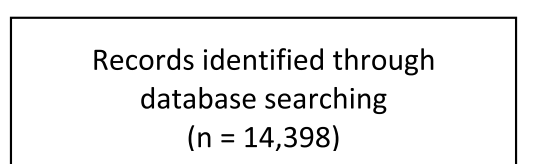

$(n=14,398)$
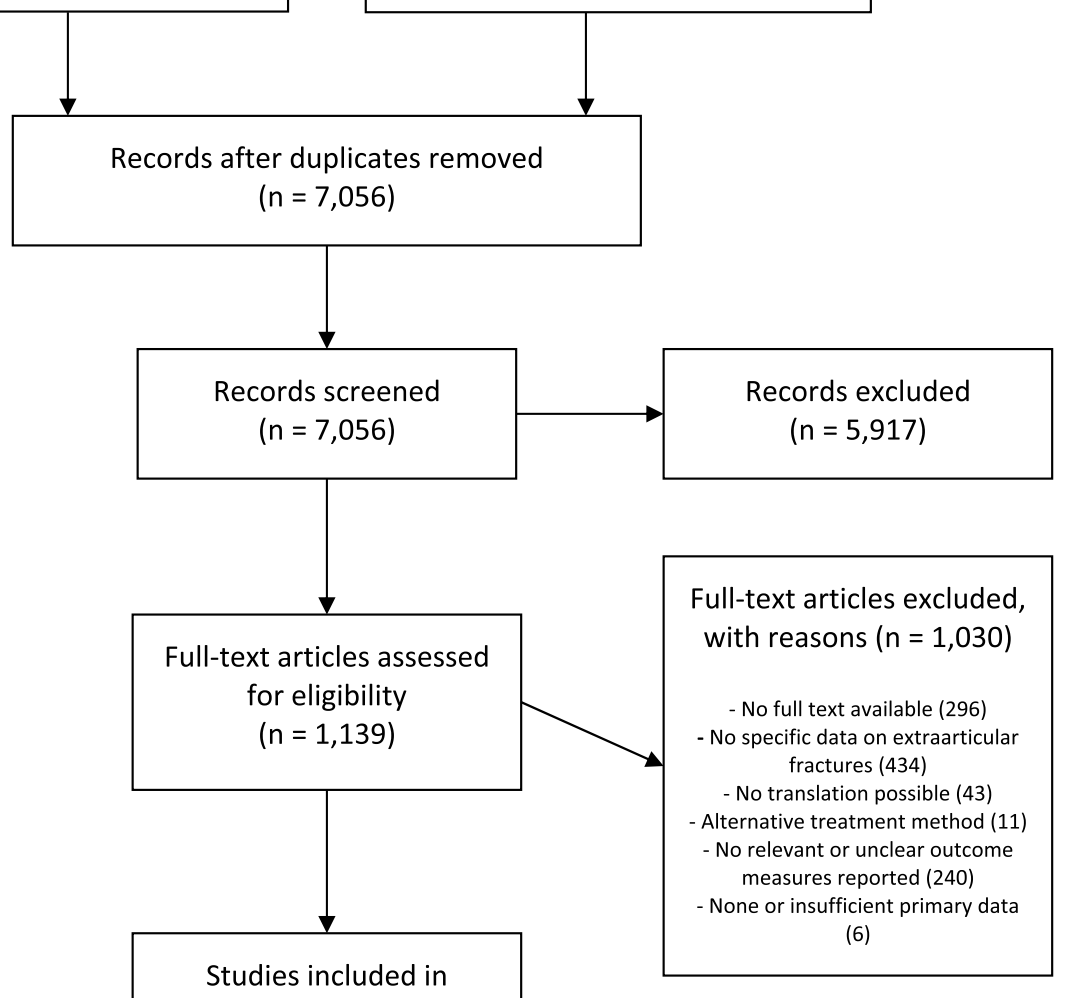

Fig. 1 Flowchart of study selection

Additional records identified through other sources $(n=2)$

quantitative synthesis

( $n=109$ studies, 136

cohorts) 
Table 1 Study subjects per treatment modality

\begin{tabular}{lllll}
\hline Treatment & $\begin{array}{l}\text { Cohorts } \\
(N)\end{array}$ & $\begin{array}{l}\text { Population } \\
(N)\end{array}$ & $\begin{array}{l}\text { Mean age } \\
(95 \% \mathrm{CI})\end{array}$ & $\begin{array}{l}\text { Proportion female } \\
(95 \% \mathrm{CI})\end{array}$ \\
\hline Plaster cast & 31 & 2185 & $61.7(53.5-69.9)$ & $78.5(71.9-84.5)$ \\
K-wires & 37 & 1525 & $57.9(47.2-68.7)$ & $67.2(56.1-77.4)$ \\
Volar plate & 41 & 2245 & $58.8(51.7-65.9)$ & $73.2(63.4-82.0)$ \\
External fixator & 16 & 428 & $50.6(31.4-69.8)$ & $77.6(63.4-89.1)$ \\
IMN & 11 & 324 & $59.3(50.0-68.6)$ & $77.6(71.3-83.1)$ \\
\hline
\end{tabular}

Data are shown as proportion with $95 \%$ CI groups (10.1\% [95\% CI 4.5-17.6\%]). Volar plating had the highest rate of carpal tunnel syndrome $(3.5 \%$ [95\% CI 2.4-4.8]) which was higher than plaster cast immobilization and K-wire fixation (0.4 [95\% CI 0.0-1.7] and 0.7 [95\% CI $0.2-1.4]$, respectively). In $6.1 \%$ of the K-wire group, the implant(s) failed (i.e., loosening or breakage of material). This was significantly higher than in the volar plate fixation group $(0.8 \%)$. There was significantly less re-dislocation in the volar plate group when compared with plaster cast (1.0\% versus $9.3 \%)$. Pooled re-intervention rates ranged from $3.8 \%$ to $5.3 \%$. Regarding these reinterventions, only one significant difference was found: the use of antibiotics was $4.2 \%$ in the $\mathrm{K}$-wire group versus $0.8 \%$ in the volar plating group. Data of all other complications and re-interventions had overlapping confidence intervals across the groups and are described in Table 2 and Table 3 and shown in Fig. 2 and Fig. 3.

\section{Radiographic outcome}

Radiographic outcomes are shown in Fig. 4 and Supplemental Table 2. Because no non-union was reported for any of the treatment methods, consolidation rates were not different. The pooled mean radial inclination, radial height, and ulnar variance were similar for all five treatments after $>12$ months' follow-up. Overall, volar plate fixation shows consistent good outcome for all four radiological measurements. Especially the ulnar variance was clearly better than the other four treatment modalities with $0.3 \mathrm{~mm},-0.1 \mathrm{~mm}, 0.3 \mathrm{~mm}$, and $0.3 \mathrm{~mm}$ at $0-3$, $3-6,6-12$, and $>12$ months after surgery, respectively. The palmar tilt in the plaster cast group was consistently lower than in other groups in all follow-up periods. The proportion of patients with a good or excellent Lidström score was reported for three treatments only: plaster cast immobilization, K-wire fixation and external fixation. Proportions were 72\% [95\% CI 45.3-92.2], 90\% [95\% CI 81.3-95.2], and 88\% [95\% CI 59.9-99.9], respectively.

\section{Functional clinical outcome}

Range of motion and grip strength are outlined in Fig. 5 and Supplemental Table 2. For several outcome parameters, none or a small number of studies provided data for analysis. Differences in range of motion and grip strength were especially found in the short-term follow-up. For example, volar plate fixation showed a relatively good grip strength (69\% of the non-injured side) and pro-/supination (81.4 and 80.0 degrees, respectively) at $0-3$ months' follow-up. Both pro- and supination were above the limit of disability for the entire follow-up period. At long-term follow-up, no clear functional differences were found across the treatment groups.

\section{Patient-reported outcomes}

A large variety of patient rated outcome measures were used in literature. This resulted in small numbers of study subjects and uncertain values. Three outcome measures that were used most often, were chosen to be analyzed and are shown in Fig. 6: Disabilities of Arm, Shoulder, and Hand (DASH) score, Gartland and Werley score, and a Visual Analog Scale (VAS) for pain. Assessment of the DASH score showed low pooled means for volar plating (13.0 points) and intramedullary fixation (15.0 points) at 0-3 months' follow-up. Again, at long term, follow-up scores were similar across the treatment groups. For both the Gartland and Werley score and the VAS for pain, an improvement was seen for all treatments over time and no clear differences were found.

\section{Discussion}

This systematic review and meta-analysis aimed to evaluate complications, re-interventions, radiographic outcomes, functional outcomes, and patient-reported outcomes of the most commonly described treatment methods for extra-articular distal radius fractures. The data do not show a clear superiority or inferiority for any of the treatments evaluated. 
Table 2 Pooled complication rates per treatment modality

\begin{tabular}{|c|c|c|c|c|c|c|}
\hline Parameter & Treatment & $\begin{array}{l}\text { Studies } \\
(N)\end{array}$ & $\begin{array}{l}\text { Population } \\
(N)\end{array}$ & $\begin{array}{l}\mathrm{Q} \\
(p \text {-value })\end{array}$ & $\begin{array}{l}\mathrm{I}^{2} \\
(95 \% \mathrm{CI})\end{array}$ & $\begin{array}{l}\text { Pooled proportion } \\
(95 \% \mathrm{CI})\end{array}$ \\
\hline \multirow[t]{5}{*}{ Any complication } & Plaster cast & 9 & 395 & $82.8(<0.001)$ & $90.3(84-94)$ & $9.0(2.0-20.3)$ \\
\hline & K-wires & 20 & 644 & $148.4(<0.001)$ & $87.2(82-91)$ & $18.5(10.9-27.6)$ \\
\hline & Volar plate & 21 & 1,203 & $63.4(<0.001)$ & $68.4(50-80)$ & $13.3(9.6-17.4)$ \\
\hline & External fixator & 11 & 324 & $24.0(0.008)$ & $58.4(19-79)$ & $18.1(11.8-25.4)$ \\
\hline & IMN & 7 & 198 & $18.5(0.005)$ & $67.6(28-85)$ & $18.2(9.5-29.0)$ \\
\hline \multirow[t]{5}{*}{ CRPS } & Plaster cast & 9 & 477 & $85.4(<0.001)$ & $90.6(84-94)$ & $2.4(0.0-9.1)$ \\
\hline & K-wires & 22 & 878 & $28.8(0.119)$ & $27.1(0-57)$ & $1.1(0.5-2.0)$ \\
\hline & Volar plate & 20 & 842 & $21.4(0.317)$ & $11.1(0-46.4)$ & $2.2(1.4-3.5)$ \\
\hline & External fixator & 10 & 304 & $12.5(0.188)$ & $27.9(0-65.4)$ & $1.4(0.4-3.4)$ \\
\hline & IMN & 8 & 214 & $5.4(0.606)$ & $0(0-58.8)$ & $1.9(0.5-4.7)$ \\
\hline \multirow[t]{5}{*}{ CTS } & Plaster cast & 7 & 373 & $0.4(0.999)$ & $0(0-0)$ & $0.4(0-1.7)^{*}$ \\
\hline & K-wires & 22 & 878 & $8.5(0.993)$ & $0(0-0)$ & $0.7(0.2-1.4)^{*}$ \\
\hline & Volar plate & 23 & 941 & $14.5(0.884)$ & $0(0-17)$ & $3.5(2.4-4.8)^{*}$ \\
\hline & External fixator & 9 & 229 & $0.8(0.999)$ & $0(0-0)$ & $0.9(0.1-3.1)$ \\
\hline & IMN & 7 & 198 & $0.7(0.994)$ & $0(0-0)$ & $1.4(0.3-4.1)$ \\
\hline \multirow[t]{5}{*}{ Infection } & Plaster cast & 10 & 449 & $0.8(1.000)$ & $0(0-0)$ & $0.5(0.1-1.7)^{*}$ \\
\hline & K-wires & 21 & 707 & $49.9(<0.001)$ & $59.9(35.3-75.1)$ & $4.7(2.5-7.6)^{*}$ \\
\hline & Volar plate & 21 & 871 & $7.7(0.994)$ & $0(0-0)$ & $0.8(0.3-1.6)^{*}$ \\
\hline & External fixator & 12 & 332 & $41.8(<0.001)$ & $73.7(53.3-85.2)$ & $10.1(4.5-17.6)^{*}$ \\
\hline & IMN & 8 & 214 & $0.7(0.998)$ & $0(0-0)$ & $0.8(0.1-3.1)^{*}$ \\
\hline \multirow[t]{5}{*}{ Deep infection } & Plaster cast & 10 & 449 & $0.8(1.000)$ & $0(0-0)$ & $0.5(0.1-1.7)$ \\
\hline & K-wires & 22 & 839 & $2.6(1.000)$ & $0(0-0)$ & $0.6(0.2-1.3)$ \\
\hline & Volar plate & 22 & 881 & $3.1(1.000)$ & $0(0-0)$ & $0.7(0.2-1.4)$ \\
\hline & External fixator & 12 & 332 & $4.3(0.959)$ & $0(0-0)$ & $0.9(0.2-2.6)$ \\
\hline & IMN & 8 & 214 & $0.7(0.998)$ & $0(0-0)$ & $1.4(0.3-3.9)$ \\
\hline \multirow[t]{5}{*}{ Implant failure } & Plaster cast & NA. & NA. & NA. & NA. & NA. \\
\hline & K-wires & 19 & 587 & $87.3(<0.001)$ & $79.4(68.5-86.5)$ & $6.1(2.5-11.1)^{*}$ \\
\hline & Volar plate & 20 & 816 & $17.1(0.582)$ & $0(0-42.3)$ & $0.8(0.3-1.5)^{*}$ \\
\hline & External fixator & 10 & 312 & $5.9(0.753)$ & $0(0-42.6)$ & $1.0(0.2-2.9)$ \\
\hline & IMN & 8 & 214 & $0.7(0.998)$ & $0(0-0)$ & $1.4(0.3-3.9)$ \\
\hline \multirow{5}{*}{$\begin{array}{l}\text { Paresthesia superficial } \\
\text { radial nerve }\end{array}$} & Plaster cast & 7 & 339 & $0.6(0.997)$ & $0(0-0)$ & $0.5(0.0-1.9)^{*}$ \\
\hline & K-wires & 20 & 674 & $17.8(0.537)$ & $0(0-44.4)$ & $1.3(0.6-2.4)^{*}$ \\
\hline & Volar plate & 18 & 637 & $25.2(0.090)$ & $32.6(0-61.9)$ & $2.2(1.0-3.9)$ \\
\hline & External fixator & 10 & 305 & $18.7(0.028)$ & $52.0(1.4-76.6)$ & $3.4(1.0-7.2)$ \\
\hline & IMN & 8 & 214 & $34.3(<0.001)$ & $79.6(60.3-89.5)$ & $10.1(2.9-21.1)^{*}$ \\
\hline \multirow[t]{5}{*}{ Tendon irritation } & Plaster cast & 9 & 395 & $0.8(0.999)$ & $0(0-0)$ & $0.5(0.1-1.8)$ \\
\hline & K-wires & 19 & 658 & $4.6(0.999)$ & $0(0-0)$ & $0.7(0.2-1.7)$ \\
\hline & Volar plate & 18 & 775 & $16.9(0.461)$ & $0.0(0-49.7)$ & $2.0(1.2-3.3)$ \\
\hline & External fixator & 9 & 229 & $0.8(0.999)$ & $0(0-0)$ & $0.9(0.1-3.1)$ \\
\hline & IMN & 6 & 182 & $3.3(0.651)$ & $0(0-62.9)$ & $1.0(0.1-3.7)$ \\
\hline \multirow[t]{5}{*}{ Tendon rupture } & Plaster cast & 8 & 353 & $0.8(0.998)$ & $0(0-0)$ & $0.5(0.1-1.9)$ \\
\hline & K-wires & 20 & 674 & $13.0(0.840)$ & $0(0-23.9)$ & $1.0(0.4-2.0)$ \\
\hline & Volar plate & 20 & 816 & $2.6(1.000)$ & $0(0-0)$ & $0.8(0.3-1.7)$ \\
\hline & External fixator & 9 & 229 & $0.8(0.999)$ & $0(0-0)$ & $0.9(0.1-3.1)$ \\
\hline & IMN & 7 & 198 & $6.4(0.381)$ & $6.1(0-73.1)$ & $1.2(0.2-3.9)$ \\
\hline
\end{tabular}


Table 2 (continued)

\begin{tabular}{lllllll}
\hline Parameter & Treatment & $\begin{array}{l}\text { Studies } \\
(N)\end{array}$ & $\begin{array}{l}\text { Population } \\
(N)\end{array}$ & $\begin{array}{l}\text { Q } \\
(p \text {-value })\end{array}$ & $\begin{array}{l}\mathrm{I}^{2} \\
(95 \% \mathrm{CI})\end{array}$ & $\begin{array}{l}\text { Pooled proportion } \\
(95 \% \mathrm{CI})\end{array}$ \\
\hline Redislocation & Plaster cast & 10 & 500 & $103.0(<0.001)$ & $91.2(86.1-94.5)$ & $\mathbf{9 . 3}(\mathbf{2 . 5}-\mathbf{1 9 . 9}) *$ \\
& K-wires & 20 & 763 & $36.8(0.008)$ & $48.4(13.3-69.3)$ & $2.3(1.0-4.1)$ \\
& Volar plate & 17 & 726 & $12.8(0.686)$ & $0(0-39.0)$ & $\mathbf{1 . 0}(\mathbf{0 . 4 - 2 . 0})^{*}$ \\
& External fixator & 10 & 249 & $6.3(0.705)$ & $0(0-46.9)$ & $2.6(1.0-5.3)$ \\
& IMN & 7 & 198 & $8.0(0.236)$ & $25.3(0-67.34)$ & $2.6(0.9-5.8)$ \\
\hline
\end{tabular}

*Non-overlapping $95 \%$ CI.

Table. 3 Pooled reintervention rates per treatment modality

\begin{tabular}{|c|c|c|c|c|c|c|}
\hline Parameter & Treatment & $\begin{array}{l}\text { Studies } \\
(N)\end{array}$ & $\begin{array}{l}\text { Population } \\
(N)\end{array}$ & $\begin{array}{l}\mathrm{Q} \\
(p \text {-value })\end{array}$ & $\begin{array}{l}\mathrm{I}^{2} \\
(95 \% \mathrm{CI})\end{array}$ & $\begin{array}{l}\text { Pooled proportion } \\
(95 \% \mathrm{CI})\end{array}$ \\
\hline \multirow[t]{5}{*}{ Any reintervention } & Nonoperative & 10 & 567 & $57.9(<0.001)$ & $84.5(73.1-91)$ & $4.6(1.1-10.2)$ \\
\hline & K-wires & 14 & 467 & $45.5(<0.001)$ & $71.4(50.1-83.4)$ & $4.1(1.4-8.2)$ \\
\hline & Volar plate & 19 & 961 & $46.2(<0.001)$ & $61.1(35.8-76.4)$ & $5.1(3.0-7.8)$ \\
\hline & External fixator & 8 & 217 & $6.2(0.521)$ & $0(0-63.6)$ & $5.3(2.8-9.1)$ \\
\hline & IMN & 8 & 214 & $11.3(0.126)$ & $38.1(0-72.7)$ & $3.8(1.7-7.2)$ \\
\hline \multirow[t]{5}{*}{ Antibiotics } & Nonoperative & 8 & 353 & $0.8(0.998)$ & $0(0-0)$ & $0.5(0.1-1.9)^{*}$ \\
\hline & K-wires & 15 & 545 & $42.5(<0.001)$ & $67.0(43.4-80.8)$ & $4.2(1.7-7.8)^{*}$ \\
\hline & Volar plate & 17 & 757 & $2.1(1.000)$ & $0(0-0)$ & $0.8(0.3-1.7)^{*}$ \\
\hline & External fixator & 9 & 229 & $36.3(<0.001)$ & $78.0(58.3-88.4)$ & $4.1(0.4-11.5)$ \\
\hline & IMN & 8 & 214 & $0.7(0.998)$ & $0(0-0)$ & $0.8(0.1-3.1)$ \\
\hline \multirow[t]{5}{*}{ Incision and Drainage } & Nonoperative & 8 & 353 & $0.78(0.998)$ & $0(0-0)$ & $0.5(0.1-1.9)$ \\
\hline & K-wires & 11 & 393 & $0.7(1.000)$ & $0(0-0)$ & $0.6(0.1-2.0)$ \\
\hline & Volar plate & 15 & 642 & $2.3(1.000)$ & $0(0-0)$ & $0.9(0.3-1.9)$ \\
\hline & External fixator & 9 & 229 & $0.8(0.999)$ & $0(0-0)$ & $0.9(0.1-3.1)$ \\
\hline & IMN & 7 & 202 & $0.6(0.997)$ & $0(0-0)$ & $0.8(0.1-3.1)$ \\
\hline \multirow[t]{5}{*}{ Re-osteosynthesis } & Nonoperative & 7 & 353 & $10.6(0.157)$ & $34.0(0-70.8)$ & $1.9(0.8-3.9)$ \\
\hline & K-wires & 13 & 429 & $9.2(0.684)$ & $0(0-43.6)$ & $1.3(0.4-2.8)$ \\
\hline & Volar plate & 17 & 781 & $6.9(0.976)$ & $0(0-0)$ & $0.6(0.2-1.5)$ \\
\hline & External fixator & 6 & 170 & $2.0(0.846)$ & $0(0-39.0)$ & $2.4(0.7-5.9)$ \\
\hline & IMN & 8 & 214 & $2.4(0.932)$ & $0(0-7.6)$ & $1.2(0.2-3.7)$ \\
\hline \multirow[t]{5}{*}{ Non-planned hardware removal } & Nonoperative & NA. & NA. & NA. & NA. & NA. \\
\hline & K-wires & 15 & 497 & $22.9(0.062)$ & $38.9(0-66.9)$ & $2.5(1.3-4.3)$ \\
\hline & Volar plate & 18 & 901 & $54.5(<0.001)$ & $68.8(49.3-80.8)$ & $5.5(3.0-8.8)$ \\
\hline & External fixator & 7 & 197 & $5.2(0.524)$ & $0(0-66.6)$ & $5.2(2.6-9.3)$ \\
\hline & IMN & 8 & 214 & $0.7(0.998)$ & $0(0-0)$ & $1.4(0.3-3.9)$ \\
\hline
\end{tabular}

*Non-overlapping 95\% CI.

The main treatment goals for extra-articular distal radius fractures are to regain an adequate wrist function and/or to release pain. In order to study and objectivize this, a multitude of questionnaires and outcome scores have been introduced over the last decades. However, which outcome parameters should be used for valid and accurate assessment of wrist function are still unclear. Also, the variety of treatment options for distal radius fractures impedes the ability to prove superiority or inferiority of the currently used treatment methods. Cochrane reviews and the American Academy of Orthopaedic Surgeons both labeled the evidence as "inconclusive" [124, 125]; [126]; [12]. This review focused on extra-articular distal radius fractures only, where both Cochrane and the AAOS stated this inconclusiveness almost a decade ago for intra-articular fractures as well. All eligible literature has been included to show trends in techniques 


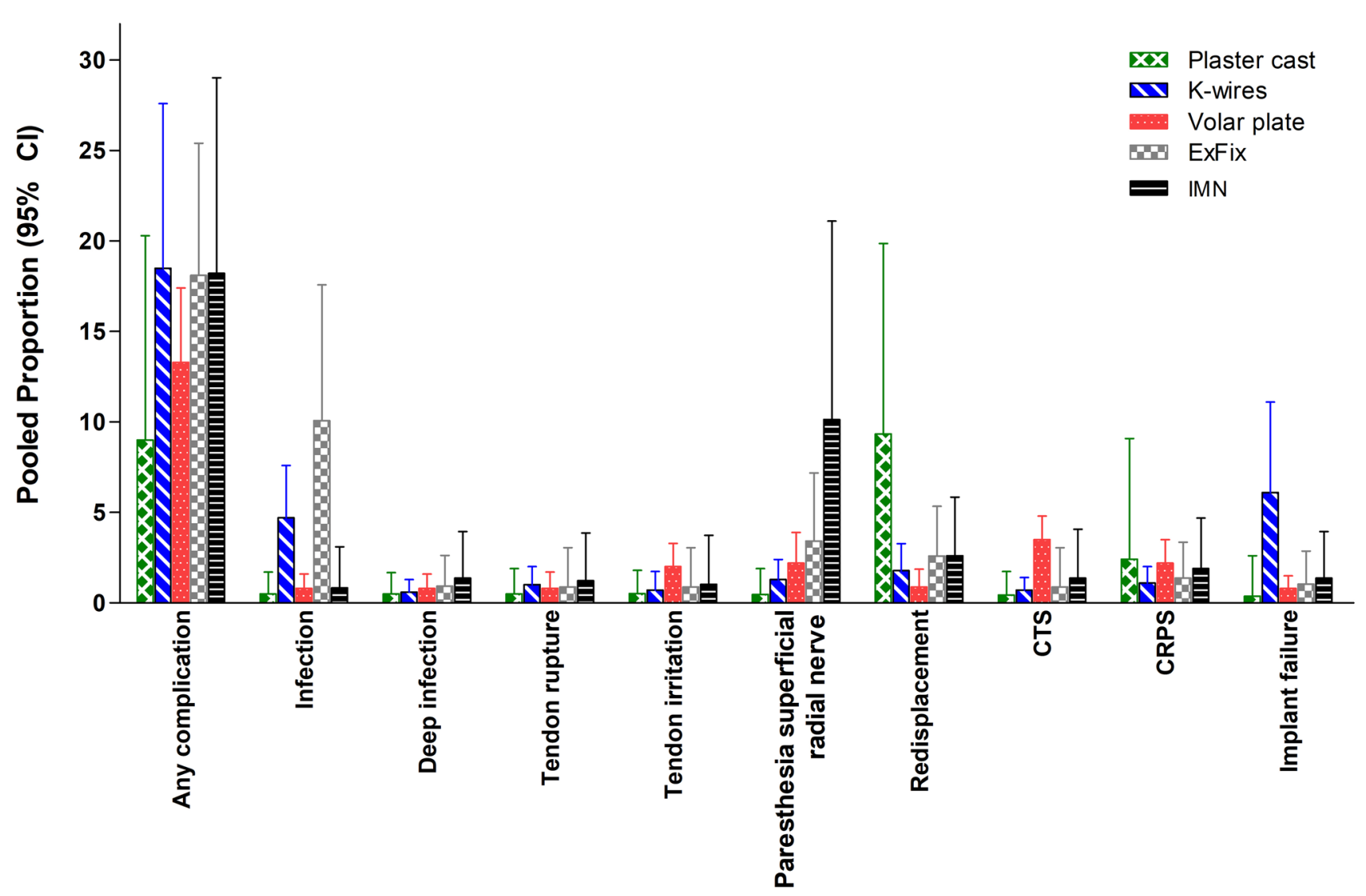

Fig. 2 Pooled complication rates per treatment modality. Data are shown as pooled proportion with 95\% CI

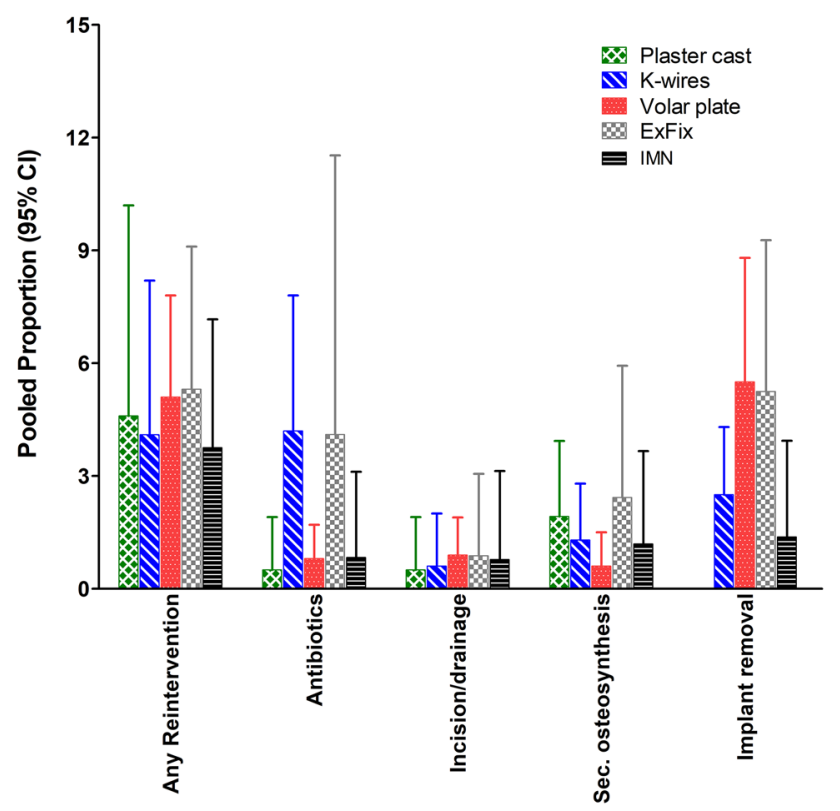

Fig. 3 Pooled re-intervention rates per treatment modality. *Early, unplanned removal due to infection, loosening, failure, or other reasons. Data are shown as pooled proportion with $95 \%$ CI. used over time. Only volar plates have been subject to significant technological improvement, this probably explains the steep increase of studies in the twenty-first century (Fig. 7).

Surprisingly, unintended outcome has been reported more frequently than intended outcome: 87 out of 136 cohorts in this study reported at least one type of complication. The overall complication and subsequent re-intervention rates are not significantly different for the five treatment modalities. However, not all studies reported consistently on all complications and re-intervention rates. Different definitions of complications and a possible extra focus on specific complications in certain studies, likely induced broad ranges of complication rates, and probably underreporting. For example, finger stiffness was described in only four studies with a rate up to $24 \%$ in a plaster cast immobilization cohort of Mardani et al. [18], where the other 105 studies did not even mention it.

No differences in functional and patient-reported outcomes at long-term follow-up ( $>12$ months) could be detected. This was also mentioned by Costa et al. and Arora et al. [5]; [77]. However, in the short term, differences in functional and patient-reported outcomes seem to exist. In all treatment groups, a lowering trend was observed after the 0-3 months' follow-up in both the 
DASH score and the Gartland \& Werley score, which means less disability and better function. In line with these findings, also an improvement in grip strength and a decrease in pain were seen in the same time period for all treatment groups. However, volar plates and intramedullary fixation had a much faster recovery than other modalities. Also, range of motion was immediately close to, or even above the limit of disability at 0-3 months' follow-up for both treatments (Fig. 5). Pronation and supination for all follow-up moments were consistently within the normal range of motion as established by, e.g. the Guides, to the Evaluation of Permanent Impairment by the American Medical Association [127]. This early recovery of patients treated with volar plating and intramedullary fixation might be an important factor in treatment choice. In current society, one might argue that long rehabilitation periods are no longer acceptable for most patients. Moreover, a strong lobby from the industry to sell implants and a high strive to restore anatomy perfectly by surgeons may push
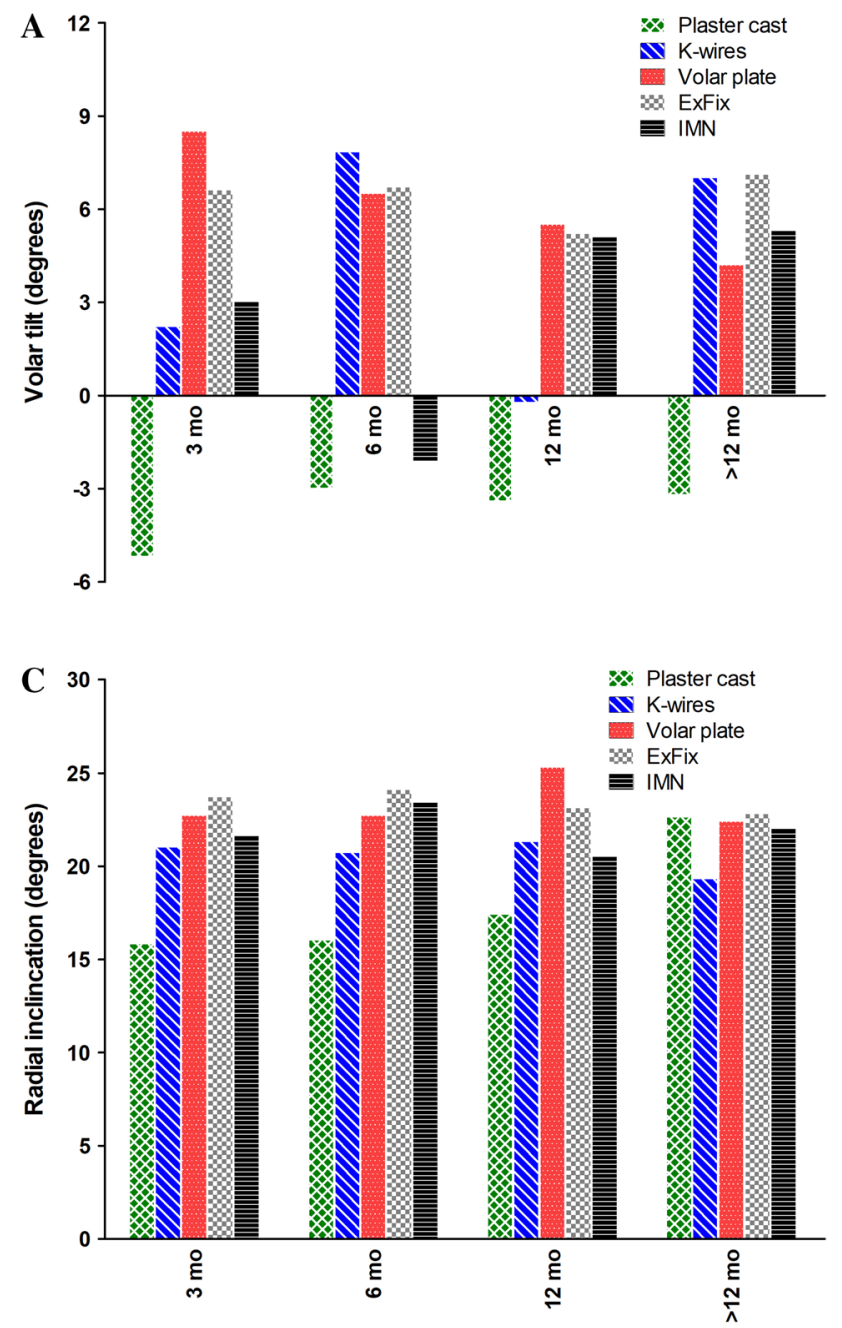

Fig. 5 Range of motion and grip strength per treatment modality. a Flexion (degrees), b Extension (degrees), c Ulnar deviation (degrees), d Radial deviation (degrees), e Pronation (degrees), f Supination (degrees), g Grip strength (\% of contralateral side). Data are shown as sample size weighted mean. The grey line represents the lowest values that will not cause any functional impairment (disability value [127])

towards surgical treatment. These arguments advocate for both short- and long-term cost-effectiveness comparison of the various treatment methods.

Radiological outcomes also seem to be in favor of volar plate fixation, as shown by a positive volar tilt, adequate radial inclination, and a negative or low ulnar variance. Radiographic parameters showed worse outcomes for plaster cast immobilization with concomitant high re-dislocation rates. Diaz-Garcia et al. published a systematic review in 2011 to examine outcomes of unstable distal radius fractures after treatment with either volar locking plate, non-bridging external fixation, bridging external fixation, percutaneous
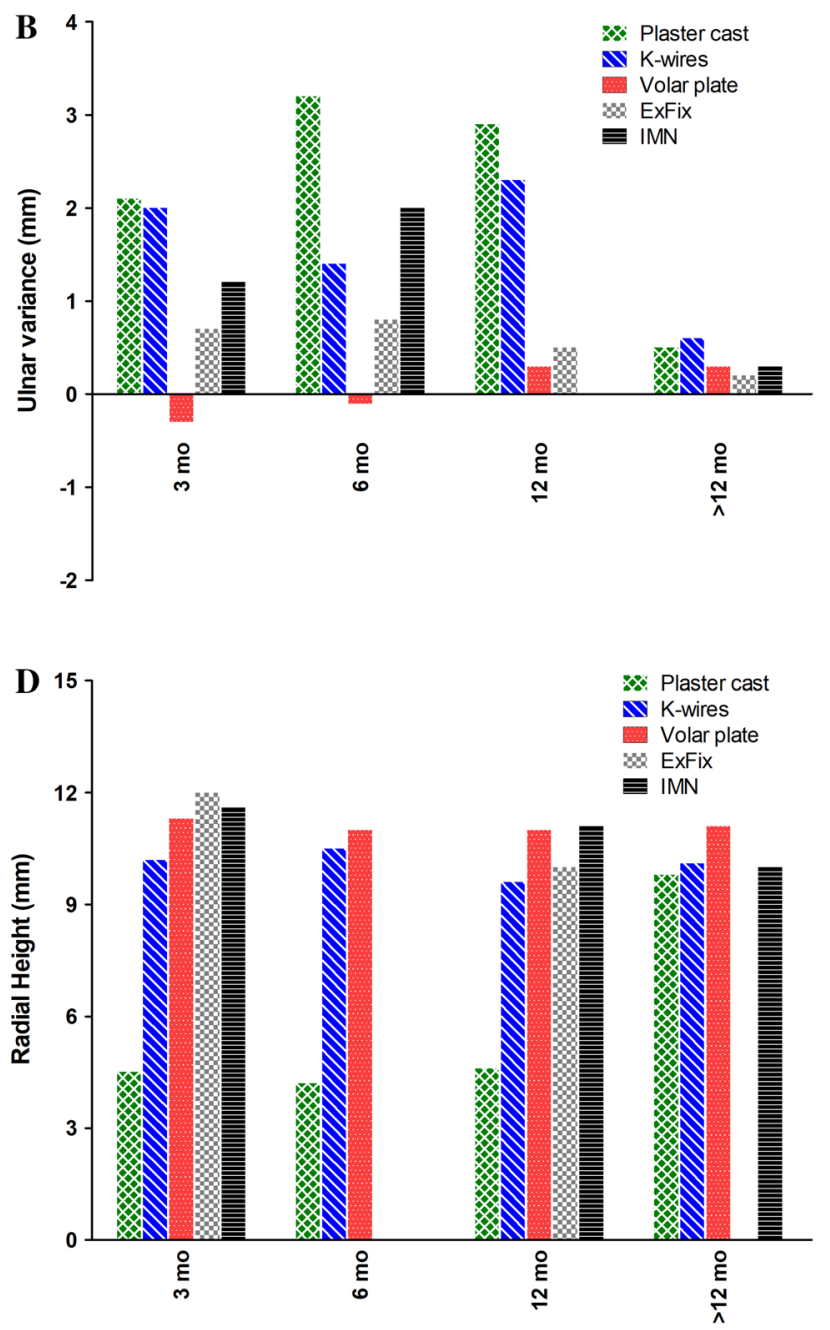

Fig. 4 Radiographic outcomes per treatment modality. a Volar tilt (degrees), b Ulnar variance (mm), c Radial inclination (degrees) and d Radial height $(\mathrm{mm})$. Data are shown as sample size weighted mean. 

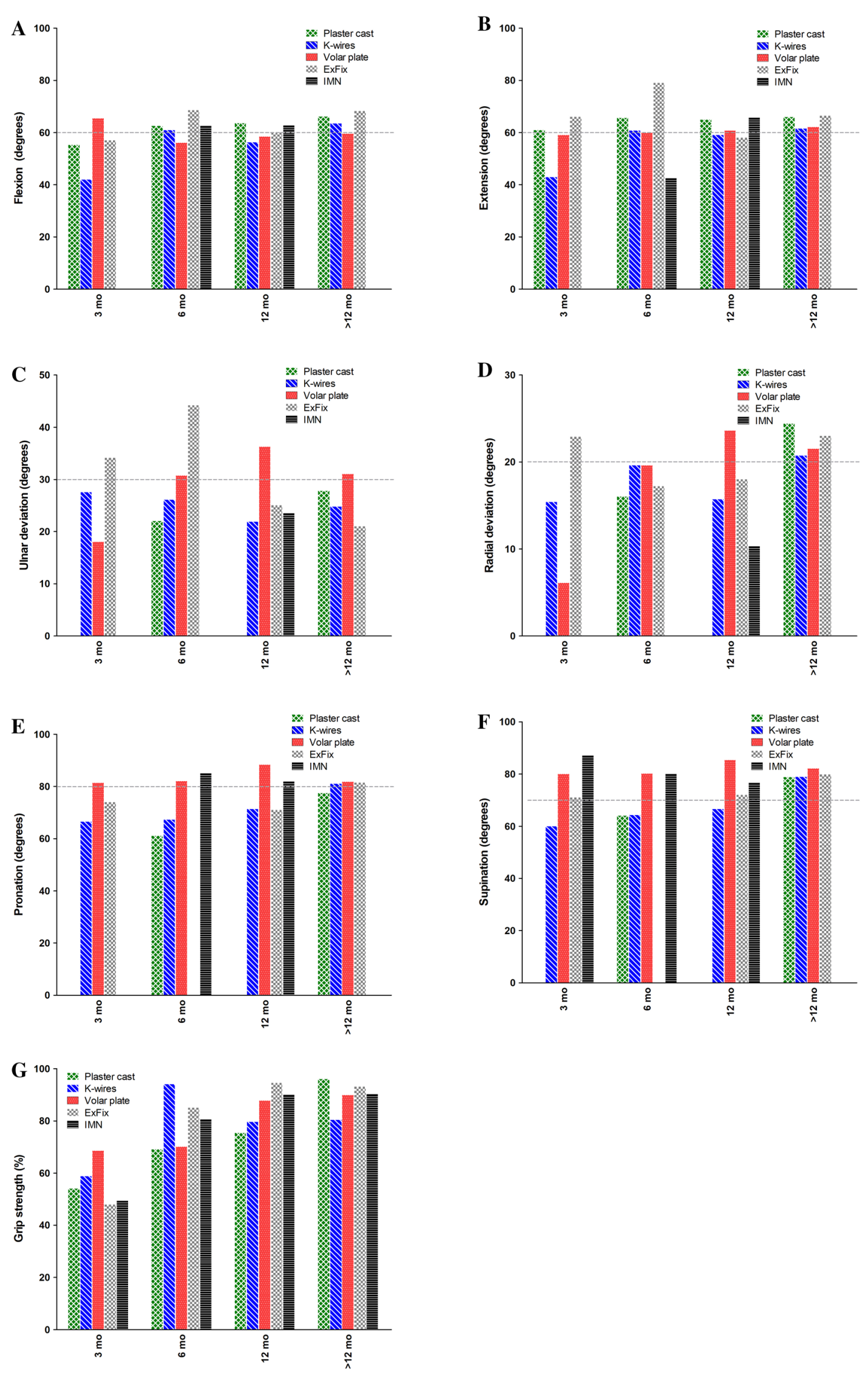

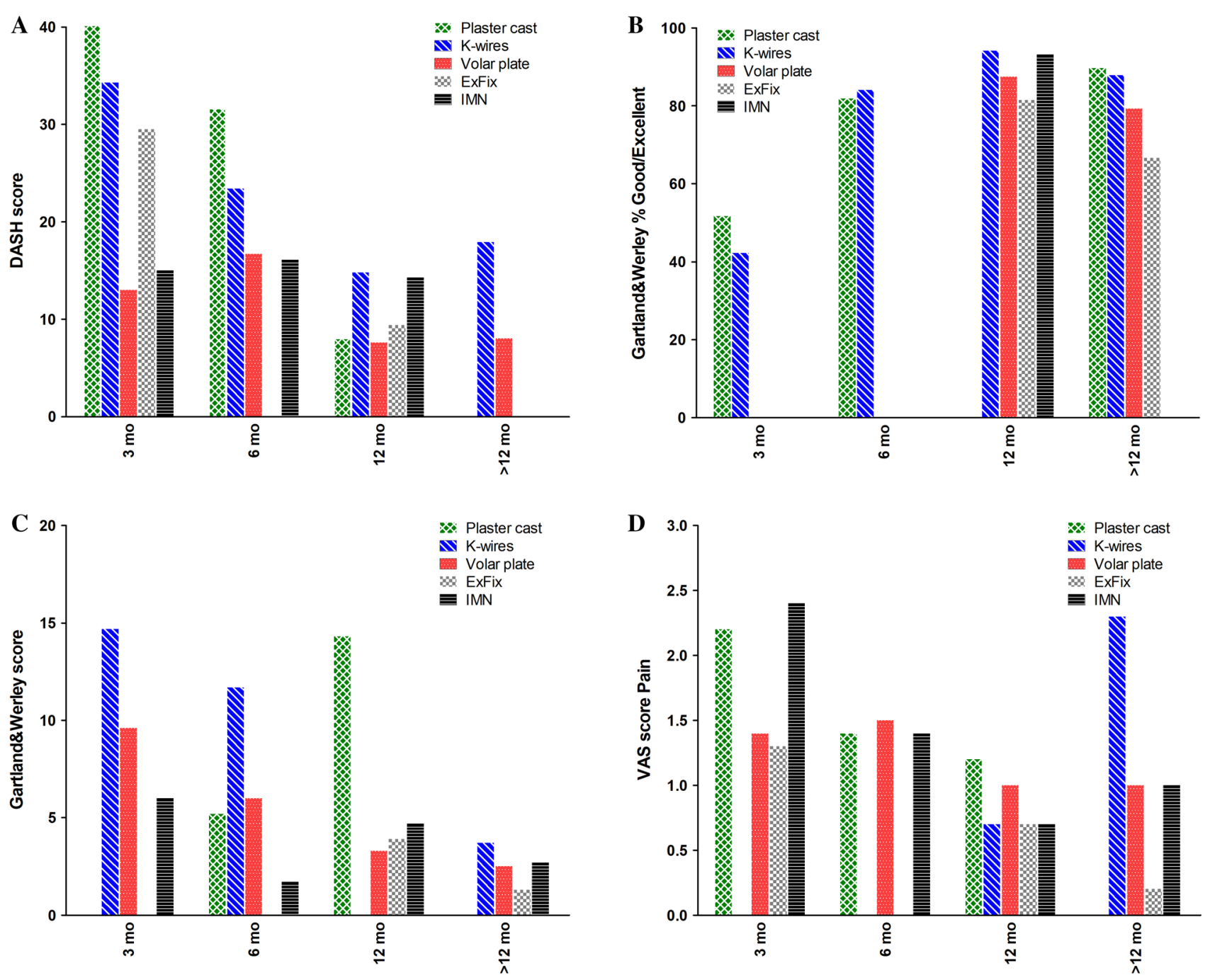

Fig. 6 Patient-reported outcome measures per treatment modality. a DASH score b Gartland \& Werley (\% good or excellent) c Gartland \& Werley Score, $\mathbf{d}$ : VAS score for pain. Data are shown as sample size weighted mean.

Kirschner-wire fixation, or plaster cast immobilization. They also found that plaster casting was associated with worse radiological outcomes than operative treatment [128]. Our systematic review reveals that since 2011 nothing has really changed.

The first thing that stood out during screening of potential studies, was the small number of studies that specifically reported on different types of distal radius fractures $(\mathrm{AO} /$ OTA or other classification systems). Many studies reported treatment outcomes for distal radius fractures in general, without any fracture classification. Distinction between different fracture types is essential to provide adequate treatment. A simple extra-articular fracture requires a different approach than a comminuted intra-articular one.

This systematic review had several limitations. First, most studies that were included were retrospective or prospective observational studies, with disappointing reporting quality for continuous data. For a proper meta-analysis of continuous data the mean, a measure of dispersion (either standard deviation, standard error or confidence interval), and sample size are necessary. Many studies in this review failed to provide these data. Moreover, the number of large, well-designed RCTs on extra-articular fractures is very low, and therefore it is very well possible to have a type 2 error. Second, selection bias in the source studies might have influenced the results of the meta-analysis, since stable and simple extra-articular fractures might have been treated nonoperatively, whereas the more dislocated and comminuted fractures might have been treated by volar plating or external fixator. However, current data did not allow for metaregression analyses. Therefore, it is not entirely certain if the current whether the findings are related to the treatment type, or can be explained by a difference in indication. Third, there was high heterogeneity in type of outcome parameters 
Fig. 7 Included studies per treatment modality per time period. Data are shown as proportion of the total included studies per treatment modality in time periods of five years $(\mathrm{N}=$ included studies)

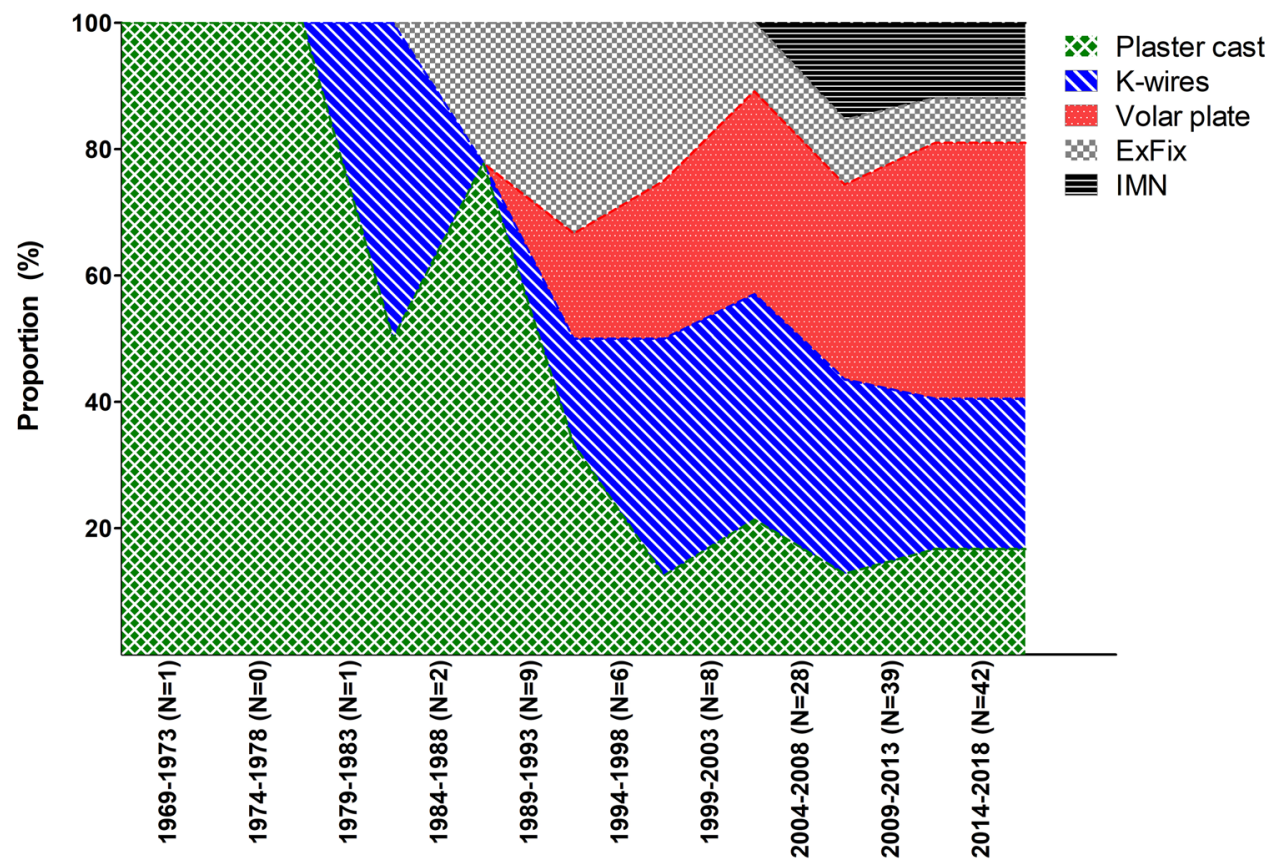

and time points of measurements reported. Goldhahn et al. mentioned already in 2014 that this heterogeneity is problematic in research on distal radius fractures and suggested a set of core domains to assess outcomes as a possible solution [129]. We have not discovered any clear improvement in data consistency since this article has been published. However, the effect of this study can still be expected over the next years due to its recent character. We agree with Goldhahn et al. that minimal requirements of outcome in the domains patient history, physical examination and radiological findings should be established and journals should only publish papers that meet these criteria. Only then the value of future systematic reviews in the field of orthopedic trauma will increase.

\section{Conclusion}

Current literature does not provide enough evidence to support superiority of a particular treatment method for extraarticular distal radius fractures, when looking at complications, re-interventions, and long-term functional outcomes. A broad range of outcome parameters have been used, which makes the data partly impossible to compare. From a methodological point of view, the quality of data used in this systematic review and subsequent conclusions that can be drawn, appear to be rather weak. This paper should therefore encourage future investigators to use more sound research methods. Consensus on outcome measures and completeness of reporting is necessary to conduct high-quality studies with standardized outcome assessment. This is needed to be able to draw sound conclusions on superiority of one of the treatment methods.

Supplementary Information The online version contains supplementary material available at https://doi.org/10.1007/s00068-021-01679-z.

Acknowledgment We thank Mr. W.M. Bramer, Biomedical information specialist at the Erasmus MC (Rotterdam, The Netherlands) for assistance with the literature search.

Author contributions All authors contributed to the study conception and design. Material preparation, data collection and analysis were performed by Guido van Oijen, Esther van Lieshout, Maarten Reijnders, and Anand Appalsamy. The first draft of the manuscript was written by Guido van Oijen and all authors commented on previous versions of the manuscript. All authors read and approved the final manuscript.

Funding No external funding was received for this study.

Availability of data and material Not applicable.

Code availability Not applicable.

\section{Declarations}

Conflict of interest The authors declare that they have no competing interests.

Open Access This article is licensed under a Creative Commons Attribution 4.0 International License, which permits use, sharing, adaptation, distribution and reproduction in any medium or format, as long as you give appropriate credit to the original author(s) and the source, provide a link to the Creative Commons licence, and indicate if changes were made. The images or other third party material in this article are included in the article's Creative Commons licence, unless indicated 
otherwise in a credit line to the material. If material is not included in the article's Creative Commons licence and your intended use is not permitted by statutory regulation or exceeds the permitted use, you will need to obtain permission directly from the copyright holder. To view a copy of this licence, visit http://creativecommons.org/licenses/by/4.0/.

\section{References}

1. Brogren E, Petranek M, Atroshi I. Incidence and characteristics of distal radius fractures in a southern Swedish region. BMC Musculoskelet Disord. 2007;8:48.

2. de Putter CE, Selles RW, Polinder S, Hartholt KA, Looman CW, Panneman MJ, et al. Epidemiology and health-care utilisation of wrist fractures in older adults in The Netherlands, 1997-2009. Injury. 2013;44(4):421-6.

3. Polinder S, Iordens GI, Panneman MJ, Eygendaal D, Patka P, Den Hartog D, et al. Trends in incidence and costs of injuries to the shoulder, arm and wrist in The Netherlands between 1986 and 2008. BMC Public Health. 2013;13:531. https://doi.org/10. 1186/1471-2458-13-531.

4. Gradl G, Mielsch N, Wendt M, Falk S, Mittlmeier T, Gierer P, et al. Intramedullary nail versus volar plate fixation of extraarticular distal radius fractures. Two year results of a prospective randomized trial. Injury. 2014;45(1):3-8. https://doi.org/10. 1016/j.injury.2013.10.045.

5. Costa ML, Achten J, Caroline P, Parsons NR, Rangan A, Tubeuf $S$, et al. UK DRAFFT: a randomised controlled triaof percutaneous fixation with kirschner wires versus volar locking-plate fixation in the treatment of adult patients with a dorsally displaced fracture of the distal radius. Health Technol Assess. 2015. https:// doi.org/10.3310/hta19170.

6. Aita MA, Vieira Ferreira CH, Schneider Ibanez D, Saraiva Marquez R, Hideki Ikeuti D, Toledo Mota R, et al. Randomized clinical trial on percutaneous minimally invasive osteosynthesis of fractures of the distal extremity of the radius. Rev bras ortop. 2014;49(3):218-26.

7. Downing ND, Karantana A. A revolution in the management of fractures of the distal radius? J Bone Joint Surg Br. 2008;90(10):1271-5. https://doi.org/10.1302/0301-620X.90B10. 21293.

8. Handoll HH, Madhok R. Surgical interventions for treating distal radial fractures in adults. Cochrane Database Syst Rev. 2003;3:CD003209. https://doi.org/10.1002/14651858.CD003 209.

9. Lutz K, Yeoh KM, MacDermid JC, Symonette C, Grewal R. Complications associated with operative versus nonsurgical treatment of distal radius fractures in patients aged 65 years and older. J Hand Surg Am. 2014;39(7):1280-6. https://doi.org/10.1016/j. jhsa.2014.04.018.

10. Egol KA, Walsh M, Romo-Cardoso S, Dorsky S, Paksima N. Distal radial fractures in the elderly: operative compared with nonoperative treatment. J Bone Joint Surg Am. 2010;92(9):1851-7.

11. NVvH (Nederlandse Vereniging voor Heelkunde). Richtlijn distale radius fracturen: Diagnostiek en behandeling. 2010. https:// www.nvpc.nl/uploads/stand/Richtlijn_Distale_radius_fracturen voor_autorisatiefase_0110201075.pdf. Accessed 18 Dec 2020.

12. AAOS (American Academy of Orthopaedic Surgeons) Clinical practice on the treatment of distal radius fractures. 2009. https:// aaos.org/globalassets/quality-and-practice-resources/distalradius/distal-radius-fractures-clinical-practice-guideline.pdf. Accessed 18 Sep 2020.
13. Bramer WM, Giustini D, de Jonge GB, Holland L, Bekhuis T. De-duplication of database search results for systematic reviews in EndNote. J Med Libr Assoc. 2016;104(3):240-3. https://doi. org/10.3163/1536-5050.104.3.014.

14. Wells G, Shea B, O'Connell D, Peterson j, Welch V, Losos M, et al. The newcastle-ottawa scale (NOS) for assessing the quality of non-randomized studies in meta-analysis. 2000.

15. Gavaghan DJ, Moore RA, McQuay HJ. An evaluation of homogeneity tests in meta-analyses in pain using simulations of individual patient data. Pain. 2000;85(3):415-24. https://doi.org/10. 1016/s0304-3959(99)00302-4.

16. Higgins JP, Thompson SG. Quantifying heterogeneity in a metaanalysis. Stat Med. 2002;21(11):1539-58. https://doi.org/10. 1002/sim.1186.

17. Higgins JP, Thompson SG, Deeks JJ, Altman DG. Measuring inconsistency in meta-analyses. BMJ. 2003;327(7414):557-60.

18. Mardani Kivi M, Asadi K, Hashemi Motlagh K, Shakiba M. Distal radius fracture, a comparison between closed reduction and long arm cast vs Closed reduction and percutaneous pinning and short arm cast. Shiraz E Med J. 2011;12(3):155-61.

19. Abbaszadegan H, Jonsson U, Von Sivers K. Prediction of instability of Colles' fractures. Acta Orthop Scand. 1989;60(6):646-50.

20. Af Ekenstam F, Jakobsson OP, Wadin K. Repair of the triangular ligament in Colles' fracture. No effect in a prospective randomized study. Acta Orthop Scand. 1989;60(4):393-6.

21. Azzopardi T, Ehrendorfer S, Coulton T, Abela M. Unstable extraarticular fractures of the distal radius. J Bone Jt Surg Ser B. 2005;87(6):837-40. https://doi.org/10.1302/0301-620x.87b6. 15608.

22. Baruah RK, Islam M, Haque R. Immobilisation of extra-articular distal radius fractures (Colles type) in dorsiflexion: the functional and anatomical outcome. J Clin Orthop Traum. 2015;6(3):16772. https://doi.org/10.1016/j.jcot.2015.03.006.

23. Basso O, Pike JM. The effect of low frequency, long-wave ultrasound therapy on joint mobility and rehabilitation after wrist fracture. J Hand Surg (GBR). 1998;23 B(1):136-9. https://doi. org/10.1016/s0266-7681(98)80248-9.

24. Bentohami A, Bijlsma TS, Goslings JC, de Reuver P, Kaufmann L, Schep NW. Radiological criteria for acceptable reduction of extra-articular distal radial fractures are not predictive for patient-reported functional outcome. J Hand Surg Eur. 2013;38(5):524-9. https://doi.org/10.1177/1753193412468266.

25. Blichert-Toft M, Jensen HK. Colles' fracture treated with modified Böhler technique. Acta Orthop Scand. 1971;42(1):45-57.

26. Eastley N, Aujla R, Khan Z. Radiographs late in the follow up of uncomplicated distal radius fractures: are they worth it? Clinical outcome and financial implications. Orthop Rev (Pavia). 2012;4(2):e20.

27. Field J, Warwick D, Bannister GC, Gibson AGF. Long-term prognosis of displaced Colles' fracture: a 10-year prospective review. Injury. 1992;23(8):529-32. https://doi.org/10.1016/00201383(92)90152-i.

28. Gupta A. The treatment of Colles' fracture. Immobilisation with the wrist dorsiflexed. J Bone Jt Surg Ser B. 1991;73(2):312-5.

29. Gutiérrez-Espinoza H, Rubio-Oyarzún D, Olguín-Huerta C, Gutiérrez-Monclus R, Pinto-Concha S, Gana-Hervias G. Supervised physical therapy vs home exercise program for patients with distal radius fracture: a single-blind randomized clinical study. J Hand Ther. 2017. https://doi.org/10.1016/j.jht.2017.02. 001.

30. Horne JG, Devane P, Purdie G. A prospective randomized trial of external fixation and plaster cast immobilization in the treatment of distal radial fractures. J Orthop Trauma. 1990;4(1):30-4.

31. Jellad A, Salah S, FBen Salah Frih Z. Complex regional pain syndrome type Incidence and risk factors in patients with fracture 
of the distal radius. Arch Phys Med Rehabil. 2014;95(3):487-92. https://doi.org/10.1016/j.apmr.2013.09.012.

32. Kulej M, Dragan S, Dragan SŁ, Krawczyk A, Płochowski J, Orzechowski W, et al. Efficacy of closed reduction and maintenance of surgical outcome in plaster cast immobilization in different types of distal radius fractures. Ortop Traumatol Rehab. 2007;9(6):577-90.

33. Kumar S, Penematsa SR, Sadri M, Deshmukh SC. How many clinic visits does it take to treat distal radial fractures? Int Orthop. 2008;32(1):91-6. https://doi.org/10.1007/s00264-006-0282-9.

34. Kumaravel S, Karthikeyan N. Clinical and radiological comparison of displaced extra articular distal radius fracture treated with plaster or external fixator. Res J Pharm Biol Chem Sci. 2015;6(2):1108-16.

35. Leone J, Bhandari M, Adili A, McKenzie S, Moro JK, Dunlop RB. Predictors of early and late instability following conservative treatment of extra-articular distal radius fractures. Arch Orthop Trauma Surg. 2004;124(1):38-41. https://doi.org/10.1007/ s00402-003-0597-6.

36. Moroni A, Vannini F, Faldini C, Pegreffi F, Giannini S. Cast vs external fixation: a comparative study in elderly osteoporotic distal radial fracture patients. Scand J Surg. 2004;93(1):64-7.

37. Rajan S, Jain S, Ray A, Bhargava P. Radiological and functional outcome in extra-articular fractures of lower end radius treated conservatively with respect to its position of immobilization. Indian j orthop. 2008;42(2):201-7.

38. Smilović J, Bilić R. Conservative treatment of extra-articular colles' type fractures of the distal radius: prospective study. Croat Med J. 2003;44(6):740-5.

39. Stein H, Volpin G, Horesh Z, Hoerer D. Cast or external fixation for fracture of the distal radius: a prospective study of 126 cases. Acta Orthop Scand. 1990;61(5):453-6.

40. Stewart HD, Innes AR, Burke FD. Factors affecting the outcome of Colles' fracture: an anatomical and functional study. Injury. 1985;16(5):289-95. https://doi.org/10.1016/0020-1383(85) 90126-3.

41. Stoffelen DVC, Broos PL. Kapandji pinning or closed reduction for extra-articular distal radius fractures. J Trauma Inj Infect Crit Care. 1998;45(4):753-7. https://doi.org/10.1097/00005373199810000-00022.

42. Subramaniam MH, Anand KK, Reddy MN. A comparative study between "closed reduction, cast immobilisation" and "closed reduction, percutaneous k-wire fixation, cast immobilisation" in distal radius fractures. J Evol Med Dental Sci. 2015;4(67):11714-23.

43. Tan V, Bratchenko W, Nourbakhsh A, Capo J. Comparative analysis of intramedullary nail fixation versus casting for treatment of distal radius fractures. J Hand Surg (USA). 2012;37(3):460-8. e1. https://doi.org/10.1016/j.jhsa.2011.10.041.

44. Tsukazaki T, Takagi K, Iwasaki K. Poor correlation between functional results and radiographic findings in Colles' fracture. J Hand Surg. 1993;18 B(5):588-91. https://doi.org/10.1016/02667681(93)90010-d.

45. Venkatesh RB, Maranna GK, Narayanappa RKB. A comparative study between closed reduction and cast application versus percutaneous K-wire fixation for extraarticular fracture distal end of radius. J Clin Diagn Res. 2016;10(2):RC05-RC9.

46. Wahlstrom $\mathrm{O}$. Treatment of Colles' fracture. A prospective comparison of three different positions of immobilization. Acta Orthop Scand. 1982;53(2):225-8.

47. Wong TC, Chiu Y, Tsang WL, Leung WY, Yam SK, Yeung $\mathrm{SH}$. Casting versus percutaneous pinning for extra-articular fractures of the distal radius in an elderly Chinese population: a prospective randomised controlled trial. J Hand Surg Eur. 2010;35(3):202-8.
48. Gutierrez-Monclus R, Gutierrez-Espinoza H, Zavala-Gonzalez J, Olguin-Huerta C, Rubio-Oyarzun D, Araya-Quintanilla F. Correlation between radiological parameters and functional outcomes in patients older than 60 years of age with distal radius fracture. Hand. 2018;2018:1558944718770203.

49. Brady O, Rice J, Nicholson P, Kelly E, O'Rourke SK. The unstable distal radial fracture one year post Kapandji intrafocal pinning. Injury. 1999;30(4):251-5. https://doi.org/10.1016/s00201383(99)00075-3.

50. Chuang PY, Yang TY, Shen SH, Tsai YH, Huang KC. The effects of dorsal cortical comminution on radiographic results following percutaneous pinning for extra-articular Colles' fracture. BioMed Res Int. 2015;2015. https://doi.org/10.1155/2015/714351.

51. Clancey GJ. Percutaneous Kirschner-wire fixation of Colles fractures: a prospective study of thirty cases. J Bone Jt Surg Ser A. 1984;66(7):1008-14.

52. Das AK, Sundaram N, Prasad TG, Thanhavelu SK. Percutaneous pinning for non-comminuted extra-articular fractures of distal radius. Indian j orthop. 2011;45(5):422-6.

53. Franck WM, Dahlen C, Amlang M, Friese F, Zwipp H. Distal radial fractures - Is the small non-bridging external fixator an alternative? A randomised, prospective study. Unfallchirurg. 2000;103(10):826-33. https://doi.org/10.1007/s001130050628.

54. Huard S, Blanchet N, Leclerc G, Rochet S, Lepage D, Garbuio P, et al. Fractures of the distal radius in patients over 70 years old: volar plates or K-wires? Chir Main. 2010;29(4):236-41. https:// doi.org/10.1016/j.main.2010.06.012.

55. Hull P, Baraza N, Gohil M, Whalley H, Mauffrey C, Brewster $\mathrm{M}$, et al. Volar locking plates versus K-wire fixation of dorsally displaced distal radius fractures-a functional outcome study. J Trauma Inj Infect Crit Care. 2011;70(6):E125-8. https://doi.org/ 10.1097/TA.0b013e3181e32714.

56. Jubel A, Prokop A, Andermahr J, Orth B, Rehm KE. Functional outcome following fixed-angle volar plating or intrafocal K-wire fixation for extraarticular fractures of the distal part of the radius: a retrospective analysis of treatment outcomes. Eur J Trauma. 2005;31(1):44-50. https://doi.org/10.1007/s00068-005-1427-z.

57. Kennedy C, Kennedy MT, Niall D, Devitt A. Radiological outcomes of distal radius extra-articular fragility fractures treated with extra-focal kirschner wires. Injury. 2010;41(6):639-42. https://doi.org/10.1016/j.injury.2010.02.003.

58. Kurup HV, Mandalia V, Singh B, Shaju KA, Mehta RL, Beaumont AR. Variables affecting stability of distal radial fractures fixed with $\mathrm{K}$ wires: a radiological study. Eur J Orthop Surg Traumatol. 2005;15(2):135-9. https://doi.org/10.1007/ s00590-005-0231-0.

59. Kurup HV, Mandalia VM, Shaju KA, Singh B, Beaumont AR. Late collapse of distal radius fractures after K-wire removal: is it significant? J Orthop Traumatol. 2008;9(2):69-72. https:// doi.org/10.1007/s10195-008-0005-7.

60. Maire N, Lebailly F, Zemirline A, Hariri A, Facca S, Liverneaux P. Prospective continuous study comparing intrafocal cross-pinning HK2 ${ }^{\circledR}$ with a locking plate in distal radius fracture fixation. Chir Main. 2013;32(1):17-24. https://doi.org/10. 1016/j.main.2012.11.001.

61. McFadyen I, Field J, McCann P, Ward J, Nicol S, Curwen C. Should unstable extra-articular distal radial fractures be treated with fixed-angle volar-locked plates or percutaneous Kirschner wires? A prospective randomised controlled trial Injury. 2011;42(2):162-6. https://doi.org/10.1016/j.injury.2010.07. 236.

62. Mirhamidi SM, Bayat FM. A prospective comparison between Kapandji and percutaneous extra-focal fxation in extra articular distal radius fractures. Int J Clin Exp Med. 2013;6(2):133-9.

63. Panthi S, Khatri K, Kharel K, Byanjankar S, Sharma JR, Shrestha $\mathrm{R}$, et al. Radiological and functional outcome of displaced colles' 
fracture managed with closed reduction and percutaneous pinning: a prospective study. Cureus. 2017;9(1):e960.

64. Rosati M, Bertagnini S, Digrandi G, Sala C. Percutaneous pinning for fractures of the distal radius. Acta Orthop Belg. 2006;72(2):138-46.

65. Rosenthal AH, Chung KC. Intrafocal pinning of distal radius fractures: a simplified approach. Ann Plast Surg. 2002;48(6):593-9.

66. Ruschel PH, Albertoni WM. Treatment of unstable extraarticular distal radius fractures by modified intrafocal Kapandji method. Tech Hand Upper Extremity Surg. 2005;9(1):7-16. https://doi.org/10.1097/01.bth.0000153633.61905.f7.

67. Sadighi A, Bazavar M, Moradi A, Eftekharsadat B. Outcomes of percutaneous pinning in treatment of distal radious fractures. Pak J Biol Sci. 2010;13(14):706-10. https://doi.org/10. 3923/pjbs.2010.706.710.

68. Schneiders W, Elenz J, Rehberg S, Rein S, Rammelt S, Zwipp $\mathrm{H}$, et al. Long-term results after Kirschner wire pinning of distal radius fractures. Unfallchirurg. 2012;115(1):38-46. https:// doi.org/10.1007/s00113-010-1857-x.

69. Szyluk K, Jasiński A, Koczy B, Widuchowski W, Widuchowski J. Results of operative treatment of unstable distal radius fractures using percutaneous $\mathrm{K}$ wire fixation. Ortop Traumatol Rehab. 2007;9(5):511-9.

70. van Aaken J, Beaulieu JY, Della Santa D, Kibbel O, Fusetti C. High rate of complications associated with extrafocal kirschner wire pinning for distal radius fractures. Chir Main. 2008;27(4):160-6. https://doi.org/10.1016/j.main.2008.05.005.

71. Vatansever A, Pişkin A, Kayalar M, Bal E, Ada S. The effect of dorsal cortical comminution on radiographic results of unstable distal radius fractures treated with closed reduction and $\mathrm{K}$-wire fixation. Acta Orthop Traumatol Turc. 2007;41(3):202-6.

72. Voigt $\mathrm{C}, \mathrm{Lill} \mathrm{H}$. What advantages does volar plate fixation have over K-wire fixation for distal radius extension fractures in the elderly? Unfallchirurg. 2006;109(10):845-54. https://doi.org/ 10.1007/s00113-006-1163-9.

73. Yang TY, Tsai YH, Shen SH, Huang KC. Radiographic outcomes of percutaneous pinning for displaced extra-articular fractures of the distal radius: a time course study. BioMed Res Int. 2014. https://doi.org/10.1155/2014/540874.

74. Manrique J, Mosquera SA, Huérfano E, Rodríguez CA, Ford E, García LA. Percutaneous pinning vs. internal fixation with locking plate: Postoperative results of comminuted fractures of the distal radius metaphysis. A randomised controlled trial. Rev Colomb Ortop Traumatol. 2017;31(3):114-9. https://doi. org/10.1016/j.rccot.2017.04.004.

75. Vasudevan PN, Lohith BM. Management of distal radius fractures-a new concept of closed reduction and standardised percutaneous 5-pin fixation. Trauma. 2018;20(2):121-30. https:// doi.org/10.1177/1460408617725104.

76. Camus EJ, van Overstraeten L. Treatment of the distal radius fractures with percutaneous pinning: evolution to the HK2 system. Eur J Orthop Surg Traumatol. 2018;2018:1-9. https://doi. org/10.1007/s00590-018-2221-z.

77. Arora R, Lutz M, Hennerbichler A, Krappinger D, Espen D, Gabl M. Complications following internal fixation of unstable distal radius fracture with a palmar locking-plate. J Orthop Trauma. 2007;21(5):316-22. https://doi.org/10.1097/BOT. 0b013e318059b993.

78. Arora R, Lutz M, Zimmermann R, Krappinger D, Gabl M, Pechlaner S. Limits of palmar locking-plate osteosynthesis of unstable distal radius fractures. Handchir Mikrochir Plast Chir. 2007;39(1):34-41. https://doi.org/10.1055/s-2007-964922.

79. Beharrie AW, Beredjiklian PK, Bozentka DJ. Functional outcomes after open reduction and internal fixation for treatment of displaced distal radius fractures in patients over 60 years of age. J Orthop Trauma. 2004;18(10):680-6. https://doi.org/10. 1097/00005131-200411000-00005.

80. Braziulis K, Rimdeika R, Kregždytė R, Tarasevičius S. Associations between the fracture type and functional outcomes after distal radial fractures treated with a volar locking plate. Medicina (Kaunas). 2013;49(9):399-402.

81. Chappuis J, Bouté P, Putz P. Dorsally displaced extra-articular distal radius fractures fixation: dorsal IM nailing versus volar plating. A randomized controlled trial. Orthop Traumatol : Surg Res. 2011;97(5):471-8. https://doi.org/10.1016/j.otsr. 2010.11.011.

82. Disseldorp DJG, Hannemann PFW, Poeze M, Brink PRG. Dorsal or volar plate fixation of the distal radius: does the complication rate help us to choose? J Wrist Sur. 2016;5(3):202-10. https://doi.org/10.1055/s-0036-1571842.

83. Gereli A, Nalbantoglu U, Kocaoglu B, Turkmen M. Comparative study of the closed reduction percutaneous cannulated screw fixation and open reduction palmar locking plate fixation in the treatment of AO type A2 distal radius fractures. Arch Orthop Trauma Surg. 2014;134(1):121-9. https://doi.org/10.1007/ s00402-013-1866-7.

84. Geyer T, Hefele K, Gülke J, Gebhard F, Mentzel M. Early results after palmar multi-axial plate osteosynthesis for treatment of distal radius fractures. Unfallchirurg. 2011;114(10):901-12.

85. Häberle S, Sandmann GH, Deiler S, Kraus TM, Fensky F, Torsiglieri T, et al. Pronator quadratus repair after volar plating of distal radius fractures or not? Results of a prospective randomized trial. Eur J Med Res. 2015. https://doi.org/10.1186/ s40001-015-0187-4.

86. Huffaker S, Earp BE, Blazar PE. The value of post-operative radiographs in clinical management of $\mathrm{AO}$ type A distal radius fractures. J hand surg, Eur. 2015;40(8):790-5.

87. Köck H, Bandl WD, Chan T. Experiences and results with the locked compression plate for 603 fractures of the distal radius. Handchir Mikrochir Plast Chir. 2005;37(5):303-8. https://doi. org/10.1055/s-2005-865897.

88. Lebailly F, Zemirline A, Facca S, Gouzou S, Liverneaux P. Distal radius fixation through a mini-invasive approach of $15 \mathrm{~mm}$. PART 1: a series of 144 cases. Eur J Orthop Surg Traumatol. 2014;24(6):877-90. https://doi.org/10.1007/s00590-013-1363-2.

89. Mignemi ME, Byram IR, Wolfe CC, Fan KH, Koehler EA, Block JJ, et al. Radiographic outcomes of volar locked plating for distal radius fractures. J Hand Surg (USA). 2013;38(1):40-8. https:// doi.org/10.1016/j.jhsa.2012.10.007.

90. Naito K, Zemirline A, Sugiyama Y, Obata H, Liverneaux P, Kaneko K. Possibility of fixation of a distal radius fracture with a volar locking plate through a $10 \mathrm{~mm}$ approach. Tech Hand Up Extrem Surg. 2016;20(2):71-6. https://doi.org/10.1097/bth. 0000000000000118.

91. Orbay JL, Fernandez DL. Volar fixed-angle plate fixation for unstable distal radius fractures in the elderly patient. J Hand Surg (USA). 2004;29(1):96-102. https://doi.org/10.1016/j.jhsa.2003. 09.015.

92. Plate JF, Gaffney DL, Emory CL, Mannava S, Smith BP, Koman LA, et al. Randomized comparison of volar locking plates and intramedullary nails for unstable distal radius fractures. J Hand Surg (USA). 2015;40(6):1095-101. https://doi.org/10.1016/j. jhsa.2015.02.014.

93. Prokop A, Jubel A, Andermahr J, Rehm KE. Do angle stable implants provide advantages? Treatment of distal radius fractures with the locking compression plate (LCP). Eur J Orthop Surg Traumatol. 2004;14(1):10-5. https://doi.org/10.1007/ s00590-003-0120-3.

94. Sakhaii M, Groenewold U, Klonz A, Reilmann H. Results after palmar plate-osteosynthesis with angularly stable T-plate in 100 distal radius fractures: A prospective study. 
Unfallchirurg. 2003;106(4):272-80. https://doi.org/10.1007/ s00113-002-0547-8.

95. Schütz M, Kolbeck S, Spranger A, Arndt-Kolbeck M, Haas NP. Palmar plating with the locking compression plate for dorsally displaced fractures of the distal radius-first clinical experiences. Zentralbl Chir. 2003;128(12):997-1002. https://doi.org/ 10.1055/s-2003-44840.

96. Solarino G, Vicenti G, Abate A, Carrozzo M, Picca G, Colella A, et al. Volar locking plate vs epibloc system for distal radius fractures in the elderly. Injury. 2016;47:S84-90. https://doi.org/ 10.1016/j.injury.2016.07.056.

97. Sonderegger J, Schindele S, Rau M, Gruenert JG. Palmar multidirectional fixed-angle plate fixation in distal radius fractures: Do intraarticular fractures have a worse outcome than extraarticular fractures? Arch Orthop Trauma Surg. 2010;130(10):1263-8. https://doi.org/10.1007/ s00402-010-1045-z.

98. Souer JS, Ring D, Jupiter J, Matschke S, Audigé L, MarentHuber M, et al. Comparison of intra-articular simple compression and extra-articular distal radial fractures. J Bone Jt Surg Ser A. 2011;93(22):2093-9. https://doi.org/10.2106/jbjs.j. 01069.

99. Souer JS, Ring D, Matschke S, Audige L, Maren-Hubert M, Jupiter J. Comparison of functional outcome after volar plate fixation with $2.4-\mathrm{mm}$ titanium versus $3.5-\mathrm{mm}$ stainless-steel plate for extra-articular fracture of distal radius. J Hand Surg (USA). 2010;35(3):398-405. https://doi.org/10.1016/j.jhsa. 2009.11.023.

100. Stevenson I, Carnegie CA, Christie EM, Kumar K, Johnstone AJ. Displaced distal radial fractures treated using volar locking plates: maintenance of normal anatomy. J Trauma Inj Infect Crit Care. 2009;67(3):612-6. https://doi.org/10.1097/TA. 0b013e3181ad8d4d.

101. Strohm PC, Müller CA, Helwig P, Mohr B, Südkamp NP. Is the locking, $3.5 \mathrm{~mm}$ Palmar T-Plate the implant of choice for displaced distal radius fractures? Z Orthop Unfall. 2007;145(3):331-7.

102. Thorninger R, Madsen ML, Waever D, Borris LC, Rolfing JHD. Complications of volar locking plating of distal radius fractures in 576 patients with 3.2 years follow-up. Injury. 2017;48(6):1104-9. https://doi.org/10.1016/j.injury.2017.03. 008 .

103. Yamashita K, Zenke Y, Sakai A, Oshige T, Moritani S, Maehara T. Comparison of functional outcome between early and delayed internal fixation using volar locking plate for distal radius fractures. J UOEH. 2015;37(2):111-9. https://doi.org/ 10.7888/juoeh.37.111.

104. Zhang X, Huang X, Shao X, Zhu H, Sun J, Wang X. A comparison of minimally invasive approach vs conventional approach for volar plating of distal radial fractures. Acta Orthop Traumatol Turc. 2017;51(2):110-7.

105. Zimmermann R, Gabl M, Pechlaner S, Sailer R, Kathrein A, Wambacher M. Distal, metaphyseal radius fractures. Results after open reduction, internal plate fixation and cortico-cancellous iliac bone grafting. Unfallchirurg. 1998;101(10):762-8. https://doi.org/10.1007/s001130050335.

106. Selles CA, Reerds STH, Roukema G, van der Vlies KH, Cleffken BI, Schep NWL. Relationship between plate removal and Soong grading following surgery for fractured distal radius. J Hand Surg Eur. 2018;43(2):137-41.

107. Shimura H, Nimura A, Fujita K, Miyamoto T. Mid-term functional outcome after volar locking plate fixation of distal radius fractures in elderly patients. J Hand Surg Asian Pac. 2018;23(2):238-42.

108. Andersen JK, Høgh A, Gantov J, Væsel MT, Hansen TB. Colles' fracture treated with non-bridging external fixation: a 1-year follow-up. J Hand Surg Eur. 2009;34(4):475-8. https:// doi.org/10.1177/1753193408102457.

109. Chilakamary VK, Lakkireddy M, Koppolu KK, Rapur S. Osteosynthesis in distal radius fractures with conventional bridging external fixator; Tips and tricks for getting them right. J Clin Diagn Res. 2016;10(1):RC05-RC8. https://doi.org/10.7860/ jcdr/2016/16696.7048.

110. Gradl G, Jupiter JB, Gierer P, Mittlmeier T. Fractures of the distal radius treated with a nonbridging external fixation technique using multiplanar K-wires. J Hand Surg (USA). 2005;30(5):960-8. https://doi.org/10.1016/j.jhsa.2005.04.014.

111. Joosten U, Joist A, Frebel T, Rieger H. The treatment of unstable fractures of the distal radius using a bridging external fixator. Results from a long-term evaluation Chirurg. 1999;70(11):1315-22.

112. Kateros K, MacHeras G, Galanakos SP, Sofianos I, Papakostas I, Papadakis SA. External fixation versus " $\pi$ " plate for distal radius fractures. J Trauma Inj Infect Crit Care. 2010;68(1):166-72. https://doi.org/10.1097/TA.0b013e3181 b0d4be.

113. Krukhaug Y, Ugland S, Lie SA, Hove LM. External fixation of fractures of the distal radius: a randomized comparison of the Hoffman compact II non-bridging fixator the Dynawrist fixator in 75 patients followed for 1 year. Acta Orthop. 2009;80(1):104-8. https://doi.org/10.1080/174536709028074 33.

114. Mehboob I, Anjum MP. Fixation of extra articular distal radial fractures with non bridging external fixator. Nepal Med Coll J. 2008;10(2):115-7.

115. Putnam MD, Fischer MD. Treatment of unstable distal radius fractures: methods and comparison of external distraction and ORIF versus external distraction-ORIF neutralization. J Hand Surg (USA). 1997;22(2):238-51.

116. Rikli DA, Kupfer K, Bodoky A. Long-term results of the external fixation of distal radius fractures. J Trauma Inj Infect Crit Care. 1998;44(6):970-6. https://doi.org/10.1097/00005373199806000-00007.

117. Schmalholz A. External skeletal fixation versus cement fixation in the treatment of redislocated Colles' fracture. Clin Orthop Relat Res. 1990;254:236-41.

118. Tyllianakis M, Mylonas S, Saridis A, Kallivokas A, Kouzelis A, Megas P. Treatment of unstable distal radius fractures with Ilizarov circular, nonbridging external fixator. Injury. 2010;41(3):306-11. https://doi.org/10.1016/j.injury.2009.09. 011.

119. Chen ACY, Cheng CY, Chou YC. Intramedullary nailing for correction of post-traumatic deformity in late-diagnosed distal radius fractures. J Orthop Traumatol. 2017;18(1):37-42. https://doi.org/10.1007/s10195-016-0422-y.

120. Chen YM, Chou YC, Cheng CY, Tsai MC, Chen ACY. Treatment of extra-articular distal radius fractures using an intramedullary nail. Formos J Musculoskelet Disord. 2012;3(4):116-20. https://doi.org/10.1016/j.fjmd.2012.09.002.

121. Dremstrup L, Skjærbæk MS, Olesen S, Hogh A, Hansen TB. Good radiological and functional results after intramedullary nailing of distal radius fractures. J Plastic Sur Hand Sur. 2013;2013:286-8.

122. Gradl G, Wendt M, Gierer P, Beck M, Mittlmeier T. Fixation of distal radial fractures with the targon DR $®$ nail. Oper Orthop Traumatol. 2009;21(4-5):472-83. https://doi.org/10. 1007/s00064-009-1911-4.

123. Takada N, Otsuka T, Kondo A, Fukuta M, Suzuki H, Yamada K. Minimally invasive osteosynthesis with an intramedullary nail for osteoporotic distal radius fractures. Eur J Orthop Surg Traumatol. 2011;21(7):503-9. https://doi.org/10.1007/ s00590-010-0743-0. 
124. Handoll HH, Madhok R. Conservative interventions for treating distal radial fractures in adults. Cochrane Database Syst Rev. 2003;2:CD000314. https://doi.org/10.1002/14651858. CD000314.

125. Handoll HH, Vaghela MV, Madhok R. Percutaneous pinning for treating distal radial fractures in adults. Cochrane Database Syst Rev. 2007;3:CD006080. https://doi.org/10.1002/14651 858.CD006080.pub2.

126. Handoll HH, Huntley JS, Madhok R. Different methods of external fixation for treating distal radial fractures in adults. Cochrane Database Syst Rev. 2008;1:CD006522. https://doi. org/10.1002/14651858.CD006522.pub2.

127. Rondinelli RD, Genovese E, Katz RT, Mayer TG, Mueller KL, Ranavaya M. AMA guides to the evaluation of permanent impairment. 6th ed. American Medical Association; 2008.
128. Diaz-Garcia RJ, Oda T, Shauver MJ, Chung KC. A systematic review of outcomes and complications of treating unstable distal radius fractures in the elderly. J Hand Surg Am. 2011;36(5):824-35. https://doi.org/10.1016/j.jhsa.2011.02. 005 .

129. Goldhahn J, Beaton D, Ladd A, Macdermid J, Hoang-Kim A, Distal Radius Working Group of the International Society for Fracture R, et al. Recommendation for measuring clinical outcome in distal radius fractures: a core set of domains for standardized reporting in clinical practice and research. Arch Orthop Trauma Surg. 2014;134(2):197-205. https://doi.org/10.1007/ s00402-013-1767-9. 